\title{
Estimation of central arterial pressure from the radial artery in patients undergoing invasive neuroradiological procedures
}

\author{
Sabino Scolletta ${ }^{1,4^{*}}$, Antoine Herpain', Salvatore Mario Romano ${ }^{2}$, Fabio Silvio Taccone ${ }^{1}$, Katia Donadello ${ }^{1,5}$, \\ Boris Lubicz ${ }^{3}$, Federico Franchi ${ }^{4}$, Keitiane Michele Kaefer ${ }^{1}$, Enrico Polati ${ }^{5}$, Jean-Louis Vincent ${ }^{1}$ and \\ Daniel De Backer ${ }^{1,6}$
}

\begin{abstract}
Backgrounds: Central arterial pressure can be derived from analysis of the peripheral artery waveform. The aim of this study was to compare central arterial pressures measured from an intra-aortic catheter with peripheral radial arterial pressures and with central arterial pressures estimated from the peripheral pressure wave using a pressure recording analytical method (PRAM).
\end{abstract}

Methods: We studied 21 patients undergoing digital subtraction cerebral angiography under local or general anesthesia and equipped with a radial arterial catheter. A second catheter was placed in the ascending aorta for central pressure wave acquisition. Central $(\mathrm{AO})$ and peripheral (RA) arterial waveforms were recorded simultaneously by PRAM for 90-180 s. During an off-line analysis, $A O$ pressures were reconstructed $\left(\mathrm{AO}_{\mathrm{rec}}\right)$ from the RA trace using a mathematical model obtained by multi-linear regression analysis. The $\mathrm{AO}_{\mathrm{rec}}$ values obtained by PRAM were compared with the true central pressure value obtained from the catheter placed in the ascending aorta.

Results: Systolic, diastolic and mean pressures ranged from 79 to $180 \mathrm{mmHg}, 47$ to $102 \mathrm{mmHg}$, and 58 to 128 $\mathrm{mmHg}$, respectively, for $\mathrm{AO}$, and 83 to $174 \mathrm{mmHg}, 47$ to $107 \mathrm{mmHg}$, and 60 to $129 \mathrm{mmHg}$, respectively, for RA. The correlation coefficients between AO and RA were $0.86(p<0.01), 0.83(p<0.01)$ and $0.86(p<0.01)$ for systolic, diastolic and mean pressures, respectively, and the mean differences $-0.3 \mathrm{mmHg}, 2.4 \mathrm{mmHg}$ and $1.5 \mathrm{mmHg}$. The correlation coefficients between $\mathrm{AO}$ and $\mathrm{AO}_{\text {rec }}$ were $0.92(p<0.001), 0.87(p<0.001)$ and $0.92(p<0.001)$, for systolic, diastolic and mean pressures, respectively, and the mean differences $0.01 \mathrm{mmHg}, 1.8 \mathrm{mmHg}$ and $1.2 \mathrm{mmHg}$. Conclusions: PRAM can provide reliable estimates of central arterial pressure.

Keywords: Central pressure waveform, Peripheral artery waveform, Arterial pressure, Pulse contour analysis

\section{Introduction}

Reliable arterial pressure monitoring is essential in critically ill patients. Physicians use the mean arterial pressure value as an index of tissue perfusion [1], but interpretation of arterial pressure waveform or derived variables is not always straightforward. In particular, the arterial pressure recorded from a femoral or radial indwelling catheter differs somewhat from the central (i.e., aortic) pressure,

\footnotetext{
*Correspondence: sabino.scolletta@dbm.unisi.it

'Department of Intensive Care, Erasme Hospital, Université Libre de Bruxelles, Brussels, Belgium

${ }^{4}$ Department of Medicine, Surgery and Neurosciences, Anesthesia and Intensive Care Unit, University Hospital of Siena, Siena, Italy Full list of author information is available at the end of the article
}

which is a key determinant of left ventricular afterload and coronary perfusion $[2,3]$. Reliable assessment of central arterial pressure has been a topic of recent investigation; in particular, aortic pressure is better related to the severity of atherosclerosis, loading conditions of the left ventricular myocardium, and left ventricular and vascular remodeling than are conventional peripheral pressures. It is also a better predictor of cardiovascular events and mortality in non-critically ill patients than peripheral pressure [4-6].

Critically ill patients experience significant variability in arterial pressure and changes in pressure wave morphology as a result of variations in arterial tone

(c) The Author(s). 2019 Open Access This article is distributed under the terms of the Creative Commons Attribution 4.0 International License (http://creativecommons.org/licenses/by/4.0/), which permits unrestricted use, distribution, and 
(e.g., from sepsis-induced vasodilation or post-surgical bleeding and vasoconstriction) [7] so that peripheral arterial pressure cannot be reliably correlated with absolute values of central arterial pressure [8]. In particular, increasing doses of vasoactive drugs may have different effects on central and peripheral arterial pressures [8-11].

Central arterial pressure can be assessed non-invasively by applanation tonometry, using a mathematical transformation (i.e., "transfer function") to estimate the aortic pressure wave from the peripheral (i.e., brachial or radial) pulse wave [2, 12-15]. In this approach, brachial arterial pressure measurement is needed to calibrate the transfer function, and aortic blood pressure is derived taking into account the timing of both the antegrade and retrograde pulse waves $[13,14]$. An alternative method is the Pressure Recording Analytical Method (PRAM), a pulse contour analysis system that can reconstruct the central arterial pressure using a mathematical model applied to the peripheral pressure wave [16]. Romano et al. showed that the function linking the central to the peripheral waveform and other variables (e.g., dicrotic pressure, diastolic pressure, heart rate, ...) was sufficient to be able to estimate the central arterial pressure from the pressure recorded at the radial site [17], avoiding the need to reconstruct every individual arterial wave point. Thus, PRAM could be helpful in ICU patients who are only monitored with an indwelling peripheral arterial catheter as central arterial pressures could be estimated using a continuous beat-to-beat approach.

The aim of this study was therefore to compare actual measured central arterial pressures (from an intra-aortic catheter), peripheral arterial pressures (from a radial catheter) and central arterial pressures estimated by PRAM in patients undergoing invasive neuroradiology procedures.

\section{Methods \\ Patients}

The Erasme University Hospital Ethics Committee approved the study (number P2011/077) and written informed consent was obtained from all patients. We prospectively studied a convenience sample of 21 adult critically ill neurological patients equipped with a 20gauge radial arterial catheter for arterial pressure monitoring and who required digital subtraction cerebral angiography for their neurological assessment and management. We excluded patients with pathologies that could affect the quality and reliability of the arterial signal, such as aortic valve pathologies, aortic aneurysms, and cardiac arrhythmias. We also excluded patients with poor quality arterial pressure signals as a result of excessive over- or underdamping of the catheter-transducer system, checked using the fast flush test (see next section for details) $[18,19]$.

\section{Study protocol}

All angiograms were performed by the same neuroradiologist (B.L.) under local or general (using propofol infusion pumps) anesthesia, depending on the patient's condition. In all patients, the $20 \mathrm{G}$ peripheral arterial line was placed on the day of the procedure. Femoral arterial access was used for introduction of the aortic catheter in each patient, with a 7F introducer followed by a $5 \mathrm{~F}$ guiding catheter placed in the ascending aorta with contrast material injected to evaluate the location of the catheter tip. After confirmation of the correct position, the catheter guide was connected to a transducer system (Edwards Lifesciences, Irvine, USA) for arterial pressure wave acquisition. After zeroing the pressure transducer, the frequency response of the arterial blood pressure transducer was checked using a fast flush test. The test consists of a brief opening of the cathetertransducer system (fast flash valve) to the high-pressure (300 mmHg) saline bag, to obtain a transient square wave in the arterial signal [18]. Closure of the fast flush valve results in pressure oscillations, allowing computation of the natural frequency and damping coefficient $[19,20]$.

The central and the peripheral arterial waveforms were displayed on two different monitors (Siemens, SC 9000) (Fig. 1). The PRAM system was connected to both monitors and the standard angiographic procedure was temporarily put on stand-by. All measurements were obtained during periods of hemodynamic stability (mean arterial pressure and heart rate variations $<5 \%)$. During this period, no changes in therapy or mechanical ventilation settings were allowed. The aortic and radial pressure waves were recorded simultaneously for 90-180 s to allow storage of a sufficient number of arterial pressure waves to construct the central arterial pressure values from the peripheral ones. At the end of the pressure wave recordings, the standard angiographic procedure was resumed and the PRAM disconnected.

\section{Pressure measurements}

During an off-line analysis, aortic systolic pressure $\left(\mathrm{SAP}_{\mathrm{ao}}\right)$, aortic diastolic pressure $\left(\mathrm{DAP}_{\mathrm{ao}}\right)$, and aortic dicrotic pressure $\left(\mathrm{Dic}_{\mathrm{ao}}\right)$ were obtained directly from the measured aortic pressure wave. Peripheral arterial pressure values were obtained from the radial pressure wave $\left(\mathrm{SAP}_{\text {peripheral }}\right.$, $\mathrm{DAP}_{\text {peripheral, }} \mathrm{Dic}_{\text {peripheral, }} \mathrm{MAP}_{\text {peripheral, }}$ and $\left.\mathrm{PP}_{\text {peripheral }}\right)$. Because measurements were obtained during periods of hemodynamic stability, the average values of all aortic and peripheral pressure waves were calculated. Blood pressure values affected by extrasystolic heart beats (if any) were excluded from the averages. Digital aortic mean pressure $\left(\mathrm{MAP}_{\mathrm{ao}}\right)$ and pulse pressure $\left(\mathrm{PP}_{\mathrm{ao}}\right)$ measurements were calculated using standard formulas $\left[\mathrm{MAP}_{\mathrm{ao}}=\left(\mathrm{SAP}_{\mathrm{ao}}+\right.\right.$ $\left.2 * \mathrm{DAP}_{\mathrm{ao}} / 3 \mathrm{DAP}_{\mathrm{ao}}+\mathrm{PP}_{\mathrm{ao}} / 3 ; \mathrm{PP}_{\mathrm{ao}}=\mathrm{SAP}_{\mathrm{ao}}-\mathrm{DAP}_{\mathrm{ao}}\right]$. 


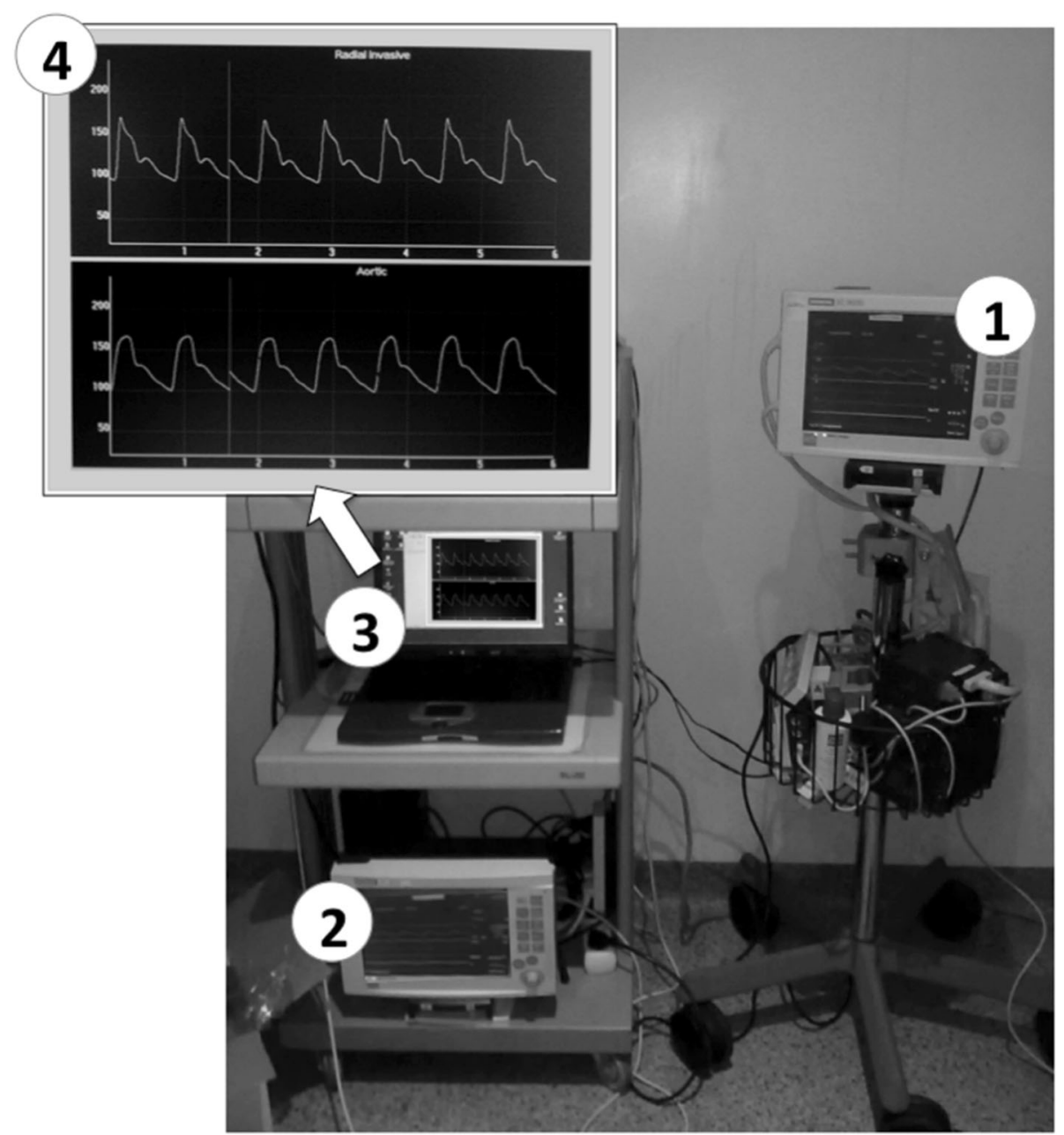

Fig. 1 The central and the peripheral arterial waveforms were displayed on two main monitors (Siemens, SC 9000) ( $1=$ central, $2=$ peripheral). PRAM software was installed on a laptop (3) that was connected to both Siemens monitors to simultaneously record the aortic and radial pressure waves for 90-180 s. The PRAM screen (4) shows the simultaneous recordings of radial (top) and aortic (bottom) pressure waves in one of the patients enrolled in the study

Aortic pressure was also reconstructed from the radial arterial trace obtained by PRAM using a mathematical model obtained from a multi-linear regression analysis (see next section). The physician who performed the offline analyses (SMR) was not aware of the reference aortic pressure measurements.

\section{Mathematical model for reconstructing the aortic pressure wave}

For all the arterial pressures recorded, the off-line analyses were conducted using the PRAM software, assessing the frequencies and resonance points of the waveform morphology for the whole cardiac cycle. With PRAM, the arterial pressure signal is acquired at 1000 points per second $\left(\mathrm{P} / \mathrm{t}, \mathrm{mmHg} \times \mathrm{sec}^{-1}\right)$ and the aortic impedance $(\mathrm{Z})$ is obtained from the morphologic analysis of both the pulsatile and continuous components of the pressure waveform. According to PRAM, $\mathrm{Z}(\mathrm{t})$ is equal to $(\mathrm{P} / \mathrm{t}) \times \mathrm{K}(\mathrm{t})$ where $\mathrm{P} / \mathrm{t}\left(\mathrm{mmHg} \times \mathrm{sec}^{-1}\right)$ is a description of the pressure wave profile (the morphology) expressed as the variations in pressure $(\mathrm{P})$ over time $(\mathrm{t})$ and $\mathrm{K}$ is a factor inversely related to the instantaneous acceleration of the vessel cross sectional area $\left(\sec ^{2} x\right.$ $\left.\mathrm{cm}^{-1}\right) \times\left(1 \mathrm{x} \mathrm{cm}^{-2}\right)$. This factor represents the non-linear relationship between changes in the vessel $\mathrm{P} / \mathrm{t}$ $\left(\mathrm{mmHg} \times \mathrm{sec}^{-1}\right)$ and the arterial pressure. $\mathrm{K}$ is obtained from the ratio between the expected (e.g., $100 \mathrm{mmHg}$ at the periphery and $90 \mathrm{mmHg}$ in the aorta) and the calculated mean arterial pressures [17].

Using data obtained during left heart catheterization in cardiac patients, Romano et al. previously showed that each point of the pressure waveform could be used to reconstruct the central aortic pressure using a multiple linear regression model to generate a transfer function from the periphery to 
the aorta $[16,17]$. The multi-linear regression analysis was performed on a dataset of 123 measurements from 41 cardiac patients undergoing heart catheterization [16]. Peripheral and central pressure waves were recorded simultaneously in each patient (three pulsations each separated by $30 \mathrm{~s})$. To work in the time domain, the single pulsations from peripheral and central records were interpolated linearly. The two signals were put in phase and the pressure and pulsation waveforms were analyzed. From each beat, samples were interpolated on a 1024 point grid. For each point a linear multiple regression was computed to obtain the single aortic waveform from the peripheral one [16]. For each variable $\left(\mathrm{SAP}_{\mathrm{rec}}, \mathrm{DAP}_{\mathrm{rec}}\right.$ and $\left.\mathrm{Dic}_{\mathrm{rec}}\right)$, the same formula was used: $P_{a o}=a_{0} \pm a_{1} \cdot b_{1} \pm a_{2} \cdot b_{2} \pm a_{3} \cdot b_{3} \pm \ldots$. , where $a_{i}$ $(i=n-1)$ are constant, and $b_{j}(j=n)$ are variables. For each point of the recorded peripheral pulse waveform, the reported multiple linear regression was applied. Independent variables were the radial pressure at the corresponding point, its first and second derivative, each point integral of radial systolic, diastolic, dicrotic and pulse pressure, heart rate, cardiac cycle efficiency $[21]$ and $\mathrm{Z}$ ( $\left.\mathrm{t} 1_{\text {instability }}\right)[16,17]$.

\section{Statistical analysis}

Data are presented as mean and standard deviation (SD), median [IQRs] or count, as appropriate. Statistical analysis was performed using the software GraphPad Prism version 5.0 (San Diego, CA, USA). For continuous data, the normal distribution was evaluated using the KolmogorovSmirnov test before a Student's paired t-test was used. The relationship between measured aortic and peripheral pressures was assessed using linear correlation analysis, and mean differences with standard errors (SE) and 95\% confidence interval (CI) were calculated. Because the reference method was the measurement of the true pressure in the aorta rather than a method with an intrinsic error [22], a linear regression analysis could be used to test the relationship between reconstructed and measured aortic pressure. The regression coefficient $\left(\mathrm{R}^{2}\right), 95 \% \mathrm{CI}$, and equation of regression were derived. In addition, in order to estimate the differences between measured and reconstructed arterial pressure values, mean bias, SE, and 95\% $\mathrm{CI}$ were calculated. Statistical significance was considered as a $\mathrm{p}$ value of $<0.05$.

\section{Results}

A total of 25 acquisitions were obtained in 21 patients (Table 1). Three patients had repeated angiography on different days (two cases 1 day later and one case 8 days later) after embolization of a cerebral aneurysm. Individual values of central aortic pressures, peripheral pressures and reconstructed aortic pressures are given in the Additional file 1: Table S1. For all the acquisitions, the frequency response of the arterial blood pressure transducer was adequate using the fast flush
Table 1 Demographic data, main diagnosis, comorbid diseases and severity scores on intensive care unit admission

\begin{tabular}{ll}
\hline Anthropometric data & \\
Age (years) & $49 \pm 15$ \\
Height (cm) & $170 \pm 9$ \\
Weight (Kg) & $81 \pm 21$ \\
Sex (M/F) & $8 / 13$ \\
APACHE II Score & $11[3-25]$ \\
SOFA Score & $3[0-10]$ \\
Main diagnosis & \\
Subarachnoid hemorrhage & 7 \\
Unruptured cerebral aneurysm & 13 \\
Arterial-venous malformation & 1 \\
Comorbid diseases & \\
Arterial hypertension & 11 \\
Obesity & 4 \\
COPD & 1
\end{tabular}

Data are presented as mean $\pm \mathrm{SD}$, median [IQRs] or count APACHE II Score Acute Physiology and Chronic Health Evaluation II, SOFA Sequential Organ Failure Assessment, COPD Chronic obstructive pulmonary disease

test, so no arterial signals were excluded from the analysis.

$\mathrm{SAP}_{\mathrm{ao}}, \mathrm{DAP}_{\mathrm{ao}}$ and $\mathrm{MAP}_{\mathrm{ao}}$ values ranged from 79 to $180 \mathrm{mmHg}, 47$ to $102 \mathrm{mmHg}$, and 58 to $128 \mathrm{mmHg}$, respectively. $\mathrm{SAP}_{\text {peripheral, }} \mathrm{DAP}_{\text {peripheral }}$, and $\mathrm{MAP}_{\text {peripheral }}$ values ranged from 83 to $174 \mathrm{mmHg}, 47$ to $107 \mathrm{mmHg}$ and 60 to $129 \mathrm{mmHg}$, respectively. The correlation coefficients between $\mathrm{SAP}_{\mathrm{ao}}-\mathrm{SAP}_{\text {peripheral, }} \mathrm{DAP}_{\mathrm{ao}}-\mathrm{DAP}_{\text {peripheral }}$, and $\mathrm{MAP}_{\mathrm{ao}}-\mathrm{MAP}_{\text {peripheral }}$ were $0.86(\mathrm{p}<0.01), 0.83(\mathrm{p}<$ $0.01)$ and $0.86(\mathrm{p}<0.01)$, respectively (Additional file 1 : Fig. S1). The differences between pressure values recorded in the aorta and the radial artery were -0.3 $\mathrm{mmHg}$ (SE $2.5 \mathrm{mmHg}$ ), $2.4 \mathrm{mmHg}$ (SE $1.6 \mathrm{mmHg}$ ), and $1.5 \mathrm{mmHg}$ (SE $1.7 \mathrm{mmHg}$ ), for systolic, diastolic and mean pressures, respectively (Additional file 1: Table S2). In eight patients, the difference between $\mathrm{SAP}_{\text {ao }}$ and $\mathrm{SAP}_{\text {peripheral }}$ was $>10 \mathrm{mmHg}$; in 4 of these patients $\mathrm{SAP}_{\text {ao }}$ was $>\mathrm{SAP}_{\text {peripheral }}$. In 7 measurements (made in 6 patients) the difference between $\mathrm{DAP}_{\mathrm{ao}}$ and $\mathrm{DAP}_{\text {peripheral }}$ was $>10 \mathrm{mmHg}$; in six of these measurements $\mathrm{DAP}_{\mathrm{ao}}$ was $>\mathrm{DAP}_{\text {peripheral }}$.

The mean values of the reconstructed pressures $\left(\mathrm{SAP}_{\text {rec }}\right.$, $\mathrm{DAP}_{\text {rec }}$, and $\mathrm{MAP}_{\text {rec }}$ ) are given in Table 2. There was excellent correlation between systolic, diastolic and mean arterial pressure values measured in the aorta and reconstructed from the radial artery $(\mathrm{r}=0.92,<0.001 ; \mathrm{r}=0.87, \mathrm{p}<0.001$; $\mathrm{r}=0.92, \mathrm{p}<0.001$ respectively). Linear regression analysis between measured and reconstructed pressures is shown in Fig. 2 and in the Additional file 1: Table S3. The mean differences between $\mathrm{SAP}_{\mathrm{ao}}$ and $\mathrm{SAP}_{\text {rec, }} \mathrm{DAP}_{\mathrm{ao}}$ and $\mathrm{DAP}_{\text {rec}}$, and 
Table 2 Mean arterial aortic pressure values recorded directly in the aorta and reconstructed from peripheral arterial waveforms

\begin{tabular}{lllllll}
\hline Variables & Aortic & Reconstructed & $P$ & Bias & SE & $95 \%$ Cl \\
\hline SAP mmHg & $111.7 \pm 24.1$ & $111.7 \pm 22.3$ & 0.99 & 0.01 & 1.8 & -3.8 to 3.8 \\
DAP mmHg & $65.5 \pm 13.5$ & $63.7 \pm 11.5$ & 0.18 & 1.8 & 1.3 & -0.9 to 4.6 \\
Dic, $m m H g$ & $90.9 \pm 19.4$ & $88.6 \pm 14.6$ & 0.21 & 2.3 & 2.0 & -1.8 to 6.5 \\
MAP mmHg & $80.9 \pm 16.6$ & $79.7 \pm 13.9$ & 0.37 & 1.2 & 1.3 & -1.5 to 4.0 \\
PP mmHg & $46.5 \pm 13.6$ & $48.9 \pm 16.2$ & 0.13 & -1.8 & 1.5 & -5.0 to 1.4
\end{tabular}

Data are expressed as mean \pm standard deviation, or mean, standard error (SE) and $95 \%$ confidence interval $(\mathrm{Cl})$

SAP Systolic arterial pressure, DAP Diastolic arterial pressure, Dic Dicrotic pressure, MAP Mean arterial pressure, $P P$ Pulse pressure

$\mathrm{MAP}_{\text {ao }}$ and $\mathrm{MAP}_{\text {rec }}$ were $0.01 \mathrm{mmHg}(\mathrm{SE} 1.8), 1.8 \mathrm{mmHg}$ (SE 1.3) and $1.2 \mathrm{mmHg}$ (SE 1.3), respectively (Table 2). $\mathrm{SAP}_{\text {rec }}$ overestimated $\mathrm{SAP}_{\text {ao }}$ by $>10 \mathrm{mmHg}$ in 5 patients and underestimated it by $>10 \mathrm{mmHg}$ in 3 patients. $\mathrm{DAP}_{\text {rec }}$ underestimated $\mathrm{DAP}_{\mathrm{ao}}$ by $>10 \mathrm{mmHg}$ in 2 patients. $\mathrm{MAP}_{\text {rec }}$ overestimated $\mathrm{MAP}_{\mathrm{ao}}$ by $>10 \mathrm{mmHg}$ in 1 patient and underestimated it by $>10 \mathrm{mmHg}$ in 2 patients (Additional file 1: Table S4).
Subgroup analyses of the central aortic, peripheral and reconstructed aortic pressures according to norepinephrine therapy, history of arterial hypertension, subarachnoid hemorrhage on admission, and sex are given in Additional file 1: Tables S5-S8.

\section{Discussion}

In stable patients undergoing an invasive neuroradiology procedure, there was a highly significant correlation between systolic, diastolic and mean arterial pressure values measured in the aorta and in the radial (peripheral) artery. There was also a significant correlation between measured values and reconstructed values obtained by PRAM using a specific mathematical model applied to the peripheral pressure wave. These data are novel since no studies have compared reconstructed aortic pressure values obtained using PRAM with directly measured values in this patient population.

Several studies have reported significant differences between central and peripheral arterial pressures, suggesting

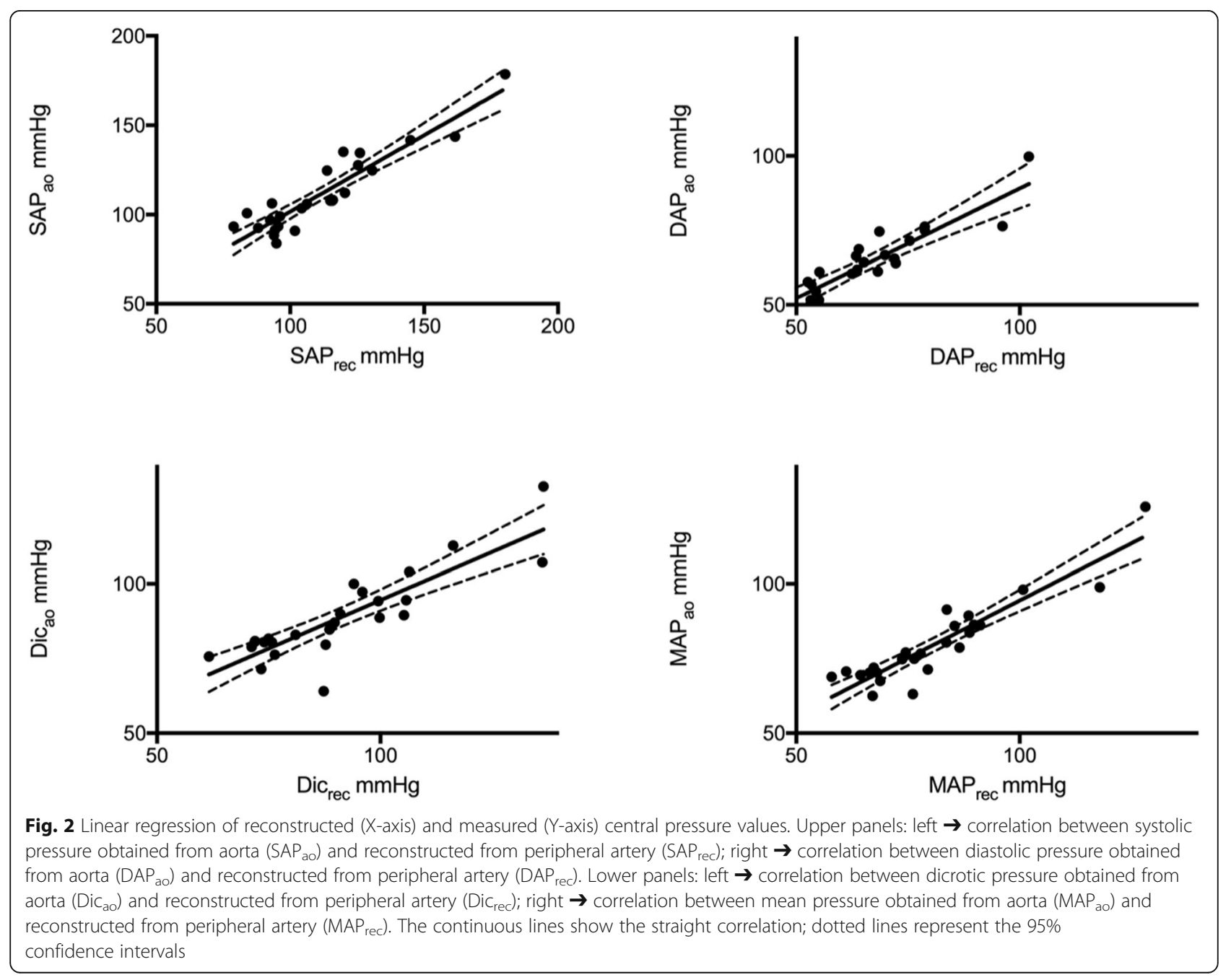


that peripheral pressure is a poor surrogate for central pressure $[2,8,12-14]$. Our results showed a good correlation between central and peripheral pressures, with a low bias between central and peripheral systolic and diastolic pressures. However, there was a greater than $10 \mathrm{mmHg}$ difference between central and peripheral systolic pressures in about $30 \%$ of the measurements ( $40 \%$ of the patients). In critically and non-critically ill patients, the differences between central and peripheral systolic pressures range between 7 and $20 \mathrm{mmHg}$ [23-25]. It has been shown in non-critically ill patients that the greater the ratio between systolic central and peripheral pressure, the poorer the outcome. Moreover, several factors have been reported to be associated with increased ratios, including comorbid diabetes, hypertension and cardiovascular disease [9, 26-29], although conflicting results exist [30]. In our sample of stable patients, we could not determine whether the bias was related to the severity of the patients' acute condition, to an underlying chronic vascular disease or to a combination of both. In addition, the degree and type (i.e., local, general, inhalational, intravenous) of analgesia and anesthesia may have impacted differently on the central and peripheral arterial vessels, decreasing the peripheral vascular tone by different amounts and causing varying degrees of vasodilation. This would explain why some patients had a radial systolic blood pressure that was lower than their central pressure, although these differences were not statistically significant. Unfortunately, our patients were not equipped with neuromonitoring systems to assess the depth of the anesthesia.

We have shown that central pressure values reconstructed from peripheral pressure waveforms recorded and analyzed using PRAM correlated well with the directly measured ascending aorta pressure. The central pressure waveform is generally obtained using applanation tonometry. Our results are similar to those from studies comparing central pressure derived from applanation tonometry with direct aortic pressure measurements. As an example, Chen et al. applied a transfer function to reconstruct central pressure in 20 patients undergoing cardiac catheterization and reported a correlation coefficient (R) of 0.97 and a bias of $0.0 \pm 3.7$ $\mathrm{mmHg}$ [12]. In a similar population $(\mathrm{n}=14)$, Karamanoglu et al. found a significant relationship $\left(R^{2}=0.95\right)$ and a difference of $2.4 \mathrm{mmHg}(\mathrm{SE}=1 \mathrm{mmHg})$ between measured and reconstructed aortic pressure [23]. A recent meta-analysis analyzed the results of 22 studies, including a total of 857 patients, which compared applanation tonometry-estimated and directly measured central aortic pressure [31]. The mean difference between measured and reconstructed systolic arterial pressure was $-1.1 \pm 4.1 \mathrm{mmHg}$ (95\% limits of agreement from -9.1 to $6.9 \mathrm{mmHg}$ ) using an invasive calibration (i.e., obtained using mean and diastolic aortic pressure values). However, the mean differences increased to $-8 \pm 10 \mathrm{mmHg}$ when the pressure waveform was calibrated non-invasively using a sphygmomanometer.
Systolic, diastolic and dicrotic pressures analyzed by PRAM from the radial artery have previously been reported to accurately estimate aortic pressures in patients undergoing cardiac catheterization [16]. The authors also reported that the true aortic pressure wave and the reconstructed one had similar shapes. In the present study, we were not able to clearly demonstrate that the reconstructed pressures obtained by PRAM were closer to central pressures than were the peripheral measurements. In fact, we found similar correlations and biases between central and reconstructed, and central and peripheral pressures.

Our study has some limitations. First, because of our small sample size, we could only perform limited subgroup analyses and cannot determine whether differences in the reconstructed pressure waves could have been associated with various clinical factors (e.g., age, cardiac disease, history of hypertension, sedative agents, tachycardia, etc....). Second, although the same fluid-filled systems were used to measure central aortic and peripheral pressures, the lengths and widths of the catheters inserted into the central and peripheral sites were different. Thus, artifacts as a result of an inappropriate dynamic response (harmonics, damping, etc) of the catheter-transducer systems may have affected the measurements. It has been shown that increasing the internal radius of the catheter decreases the damping coefficient [32]. Romagnoli et al. showed that the arterial catheter diameter (20- versus 18 gauge) was one of the parameters independently associated with underdamping/resonance; the smaller the diameter of the catheter, the greater the damping coefficient of the catheter-transducer system [32]. We are unable to state whether our results would have been the same using identical catheters and fluid-filled systems to measure the aortic and radial pressures. Pauca et al. previously used similar catheters (20G) to record the pressure waveforms in both the aorta and the radial artery in patients undergoing cardiac surgery. They reported similar mean differences to those recorded in the present study, for mean and diastolic pressures but not for systolic pressure, which resulted in higher values at the peripheral site; this is in agreement with basic hemodynamic principles [24]. However, by contrast with our study, Pauca et al. enrolled cardiac surgical patients undergoing standardized general anesthesia and analgesia [24]. Unfortunately, we did not record the natural frequency and damping coefficient obtained using the fast flush test. In addition, we did not use a high fidelity catheter [32]. Chen et al. demonstrated agreement and bias between measured and reconstructed aortic pressure using a micromanometer to measure aortic pressure similar to our study [12]; however, in the majority of studies, 
radial pressure was measured using a fluid-filled catheter. Third, we used the mean arterial pressure calculated from the standard formula instead of the value computed from the average of the arterial waveform. We chose this method because standard monitors used in clinical practice calculate the mean arterial pressure from systolic and diastolic pressures. Fourth, we investigated a population of stable patients undergoing the same procedure and the agreement between measured and reconstructed arterial pressure may differ more substantially in less stable patients. For example, in hypertensive, hypotensive and septic patients and in patients treated with vasoactive agents, changes in arterial tone may have different effects on the characteristics of arterial wall and waveform morphology due to alteration in reflected waves [7, 33-35]. Finally, we reconstructed central aortic pressure only from radial traces. Arterial pressure can have different values and waveforms at different sites [2], and we cannot be sure that applying PRAM on femoral arterial signals would give similar results.

In conclusion, in the present study performed in stable patients during cerebral angiography, central arterial pressure values reconstructed from the radial artery pressure wave using PRAM were similar to those measured directly in the aorta; however, given the small differences between measured peripheral and measured aortic pressures, we were unable to demonstrate conclusively that the PRAM technique could reconstruct the central arterial pressure. Further studies are warranted in patients with larger differences between measured peripheral and aortic pressures (e.g., vascular surgical or diabetes patients) to confirm validity. In addition, studies should also assess whether this method could be helpful in critically ill patients with different conditions that may affect the pressure wave shape (e.g., sepsis, cardiac failure, trauma, hemorrhage) and may increase the risk of bias between measured and estimated pressures.

\section{Additional file}

Additional file 1: Table S1. Individual values of central aortic pressure, peripheral pressure and aortic reconstructed pressure. Figure S1. Correlations between systolic (SAP ao), diastolic ( $\left.\mathrm{DAP}_{\mathrm{ao}}\right)$ and mean (MAP ao arterial pressure recorded in the aorta and those recorded in the radial artery (SAP peripheral, DAP peripheral, MAP peripheral). Dotted lines represented the 95\% confidence intervals. Table S2. Differences between arterial. pressures recorded in the aorta and those recorded in the radial artery. Table S3. Linear regression of measured and reconstructed central arterial pressure values. Table S4. Numbers of patients with $>10 \mathrm{mmHg}$ differences between central and reconstructed pressures. Table S5. Arterial blood pressure according to norepinephrine therapy. Table $\mathbf{S 6 .}$ Arterial blood pressure according to the presence of chronic hypertension, defined as hypertension in antihypertensive therapy. Table S7. Arterial blood pressure according to the presence of subarachnoid hemorrage (SAH) on admission. Table S8. Arterial blood pressure according to patient sex. (DOCX $133 \mathrm{~kb})$

\section{Abbreviations}

AO: Central arterial waveforms; DAP ao: Aortic diastolic pressure; DAP peripheral: Radial diastolic pressure; DAP rec: Reconstructed diastolic pressure; $\mathrm{DiC}_{\mathrm{a}}$ : Aortic dicrotic pressure; Dic $\mathrm{c}_{\text {pripheral: }}$ Radial dicrotic pressure; ICU: Intensive care unit; MAP ao: Aortic mean pressure; $M A P_{\text {peripheral: Radial }}$ mean pressure; $\mathrm{MAP}_{\text {rec: }}$ : Reconstructed mean pressure; $\mathrm{PP}_{\mathrm{ao}}$ : Aortic pulse pressure; $\mathrm{PP}_{\text {peripheral: }}$ Radial pulse pressure; PRAM: Pressure Recording Analytical Method; RA: Peripheral arterial waveforms; $\mathrm{SAP}_{\mathrm{ao}}$ : Aortic systolic pressure; SAP peripheral: Radial systolic pressure; SAP rec: Reconstructed systolic pressure; Z: Aortic impedance

\section{Acknowledgements \\ None.}

\section{Authors' contributions}

SS and DDB designed the study. AH, FST, KD, BL, KMK and FF collected and analyzed the data. SS, FST, FF, SMR, DDB, and JLV interpreted the data and wrote the manuscript. EP and KD contributed to review the manuscript. FF and SMR performed the statistical analysis. SS takes the full responsibility for the integrity of the work. All authors read and approved the final version of the manuscript.

\section{Funding}

This study was supported by no funding.

\section{Availability of data and materials}

The datasets used and/or analysed during the current study are available from the corresponding author on reasonable request.

\section{Ethics approval and consent to participate}

The Erasme University Hospital Ethics Committee approved the study (number P2011/077) and written informed consent was obtained from all patients.

\section{Consent for publication}

We have not images entirely unidentifiable and no details on individuals reported within the manuscript.

\section{Competing interests}

SM Romano is the inventor and the patent holder of the Pressure Recording Analytical Method (PRAM).

S. Scolletta received lecture fees and research grants from Vygon and Edwards Lifesciences. F. Franchi received lecture fees from Vygon.

The other authors declare that they have no competing interests.

\section{Author details}

'Department of Intensive Care, Erasme Hospital, Université Libre de Bruxelles, Brussels, Belgium. ${ }^{2}$ Department of Heart and Vessels, University of Florence, Azienda Ospedaliero-Universitaria Careggi, Florence, Italy. ${ }^{3}$ Department of Interventional Neuroradiology, Erasme Hospital, Université Libre de Bruxelles, Brussels, Belgium. ${ }^{4}$ Department of Medicine, Surgery and Neurosciences, Anesthesia and Intensive Care Unit, University Hospital of Siena, Siena, Italy. ${ }^{5}$ Anesthesia and Intensive Care B, Department of Surgery, Dentistry, Paediatrics and Gynaecology, University of Verona, AOUI, University Hospital Integrated Trust of Verona, Verona, Italy. ${ }^{6}$ Department of Intensive Care, CHIREC Hospitals, Université Libre de Bruxelles, Brussels, Belgium.

Received: 15 June 2019 Accepted: 26 August 2019

Published online: 04 September 2019

References

1. Rhodes A, Evans LE, Alhazzani W, Levy MM, Antonelli M, Ferrer R, et al. Surviving sepsis campaign: international guidelines for Management of Sepsis and Septic Shock: 2016. Intensive Care Med. 2017:43:304-77.

2. Hashimoto J, Ito S. Central diastolic pressure decay mediates the relationship between aortic stiffness and myocardial viability: potential implications for aortosclerosis-induced myocardial ischemia. J Hypertens. 2017;35(10):2034-43.

3. Bello H, Norton GR, Ballim I, Libhaber CD, Sareli P, Woodiwiss AJ. Contributions of aortic pulse wave velocity and backward wave pressure to 
variations in left ventricular mass are independent of each other. J Am Soc Hypertens. 2017;11(5):265-74.

4. Sztrymf B, Jacobs F, Chemla D, Richard C, Millasseau SC. Validation of the new Complior sensor to record pressure signals non-invasively. J Clin Monit Comput. 2013;27(6):613-9.

5. Vlachopoulos C, Aznaouridis K, O'Rourke MF, Safar ME, Baou K, Stefanadis C. Prediction of cardiovascular events and all-cause mortality with central haemodynamics: a systematic review and meta-analysis. Eur Heart J. 2010;31:1865-71.

6. Pini R, Cavallini MC, Palmieri V, Marchionni N, Di Bari M, Devereux RB, et al, Central but not brachial arterial pressure predicts cardiovascular events in an unselected geriatric population: the ICARe Dicomano study. J Am Coll Cardiol. 2008:51(25):2432-9.

7. De Backer D, Annane D. Beta-blockers in septic shock to optimize hemodynamics? We are not sure. Intensive Care Med. 2016:42(10):1613-4.

8. Hatib F, Jansen JR, Pinsky MR. Peripheral vascular decoupling in porcine endotoxic shock. J Appl Physiol. 2011:111(3):853-60.

9. Williams B, Lacy PS, Thom SM, Cruickshank K, Stanton A, Collier D, et al. CAFE investigators; Anglo-Scandinavian cardiac outcomes trial investigators; CAFE steering committee and writing committee. Differential impact of blood pressure-lowering drugs on central aortic pressure and clinical outcomes: principal results of the conduit artery function evaluation (CAFE) study. Circulation. 2006;113(9):1213-25.

10. Roman MJ, Devereux RB, Kizer JR, Lee ET, Galloway JM, Ali T, et al. Central pressure more strongly relates to vascular disease and outcome than does brachial pressure: the strong heart study. Hypertension. 2007;50(1):197-203.

11. Chirinos JA, Kips JG, Jacobs DR Jr, Brumback L, Duprez DA, Kronmal R, et al. Arterial wave reflections and incident cardiovascular events and heart failure: MESA (multiethnic study of atherosclerosis). J Am Coll Cardiol. 2012; 60(21):2170-7.

12. Chen $\mathrm{CH}$, Nevo E, Fetics B, Pak PH, Yin FC, Maughan WL, et al. Estimation of central aortic pressure waveform by mathematical transformation of radial tonometry pressure. Validation of generalized transfer function. Circulation. 1997:95(7):1827-36.

13. Guala A, Tosello F, Leone D, Sabia L, D'Ascenzo F, Moretti C, et al. Multiscale mathematical modeling vs. the generalized transfer function approach for aortic pressure estimation: a comparison with invasive data. Hypertens Res. 2018. https://doi.org/10.1038/s41440-018-0159-5.

14. Millasseau S, Agnoletti D. Non-invasive estimation of aortic blood pressures: a close look at current devices and methods. Curr Pharm Des. 2015;21:709-18.

15. Sharman JE, Avolio AP, Baulmann J, et al. Validation of non-invasive central blood pressure devices: ARTERY society task force consensus statement on protocol standardization. Eur Heart J. 2017;38(37):2805-12.

16. Romano SM, Chiostri M, Pistolesi M, Gensini GF, Viroli L, Castellani W, et al. The reconstruction of the waveform in the ascending aorta derived from the finger measured non invasively. Med Biol Eng Comput. 1999;37:319-20 abstract book - congress presentation.

17. Romano SM, Pistolesi M. Assessment of cardiac output from systemic arterial pressure in humans. Crit Care Med. 2002;30(8):1834-41.

18. Kleinman B, Powell S, Kumar P, Gardner RM. The fast flush test measures the dynamic response of the entire blood pressure monitoring system. Anesthesiology. 1992;77(6):1215-20.

19. Romagnoli S, Franchi F, Ricci Z, Scolletta S, Payen D. The pressure recording analytical method (PRAM): technical concepts and literature review. J Cardiothorac Vasc Anesth. 2017;31(4):1460-70.

20. Gardner RM. Direct blood pressure measurement: dynamic response requirements. Anesthesiology. 1981;54:227-36.

21. Romano SM. Cardiac cycle efficiency: a new parameter able to fully evaluate the dynamic interplay of the cardiovascular system. Int J Cardiol. 2012; 155(2):326-7.

22. Bland JM, Altman DG. Statistical methods for assessing agreement between two methods of clinical measurement. Lancet. 1986;1:307-10.

23. Karamanoglu M, O'Rourke MF, Avolio AP, Kelly RP. An analysis of the relationship between central aortic and peripheral upper limb pressure waves in man. Eur Heart J. 1993;14(2):160-7.

24. Pauca AL, O'Rourke MF, Kon ND. Prospective evaluation of a method for estimating ascending aortic pressure from the radial artery pressure waveform. Hypertension. 2001;38(4):932-7.

25. Pauca AL, Kon ND, O'Rourke MF. The second peak of the radial artery pressure wave represents aortic systolic pressure in hypertensive and elderly patients. Br J Anaesth. 2004;92(5):651-7.
26. Avolio AP, Van Bortel LM, Boutouyrie P, Cockcroft JR, McEniery CM, Protogerou AD, et al. Role of pulse pressure amplification in arterial hypertension: experts' opinion and review of the data. Hypertension. 2009; 54(2):375-83.

27. Agnoletti D, Zhang Y, Borghi C, Blacher J, Safar ME. Effects of antihypertensive drugs on central blood pressure in humans: a preliminary observation. Am J Hypertens. 2013;26(8):1045-52.

28. McEniery CM, Yasmin MDB, Munnery M, Wallace SM, Rowe CV, Cockcroft JR, et al. Central pressure: variability and impact of cardiovascular risk factors: the Anglo-Cardiff collaborative trial II. Hypertension. 2008;51(6):1476-82.

29. Kostapanos M, McEniery CM, Wilkinson IB. Clinical relevance of central blood pressure - a critical review. Vasa. 2016;45(6):451-60

30. Mitchell GF, Hwang SJ, Larson MG, Hamburg NM, Benjamin EJ, Vasan RS, et al. Transfer function-derived central pressure and cardiovascular disease events: the Framingham heart study. J Hypertens. 2016;34(8):1528-34.

31. Cheng HM, Lang D, Tufanaru C, Pearson A. Measurement accuracy of noninvasively obtained central blood pressure by applanation tonometry: a systematic review and meta-analysis. Int J Cardiol. 2013;167(5):1867-76.

32. Romagnoli S, Ricci Z, Quattrone D, Tofani L, Tujjar O, Villa G, et al. Accuracy of invasive arterial pressure monitoring in cardiovascular patients: an observational study. Crit Care. 2014;18(6):644

33. Greco E, Peruzzi M, Biondi-Zoccai G, Frati G, Romano SM. Heart rate reduction with esmolol is associated with improved arterial elastance in patients with septic shock: a prospective observational study. Intensive Care Med. 2016;42(10):1528-34.

34. Li Y, Gu H, Fok H, Alastruey J, Chowienczyk P. Forward and backward pressure waveform morphology in hypertension. Hypertension. 2017;69(2):375-81.

35. Monge Garcia MI, Jian Z, Settels JJ, Hatib F, Cecconi M, Pinsky MR. Reliability of effective arterial elastance using peripheral arterial pressure as surrogate for left ventricular end-systolic pressure. J Clin Monit Comput. 2018;Dec 14. https://doi.org/10.1007/s10877-018-0236-y.

\section{Publisher's Note}

Springer Nature remains neutral with regard to jurisdictional claims in published maps and institutional affiliations.

Ready to submit your research? Choose BMC and benefit from:

- fast, convenient online submission

- thorough peer review by experienced researchers in your field

- rapid publication on acceptance

- support for research data, including large and complex data types

- gold Open Access which fosters wider collaboration and increased citations

- maximum visibility for your research: over $100 \mathrm{M}$ website views per year

At BMC, research is always in progress.

Learn more biomedcentral.com/submissions 